attributional work in science. The distinction between men and the world on which they act is not to be a resource but a topic. Again, we cannot explain social action by referring to human beings as active and machines or bacteria as acted upon. This radically anti-reductionist and anti-realist stance arises from a French semiotic tradition that is neither well known in Anglophone scholarship nor adequately explained in this book. Is it a methodology and an analyst's conceit or is it an ontology? Is it a position about 'external reality' (as humble Anglo-Saxon empiricists think of it) or is it about the self-contained 'signifiers' of semiotic discourse?

One has to think that this semiotic perspective, when properly explained and understood, will resolve evident contradictions in Latour's work between programmatic injunctions and empirical practice. Thus, his abundant references to the professional "interests" of physicians are presumably not what they seem to be to Anglophone readers. And this new semiotic idiom will also explain how the use of such approved latourian locutions as "social groups", "networks" and "strong and weak associations" is different in kind to that of supposedly banned explanatory entities such as "social context" or "social interests".

Not just historians, sociologists and philosophers, but also scientists and members of lay society, have traditionally been interested in the relations between entities they call science and society. Latour instructs us that we have not just been giving bad answers but asking bad questions. The price of assimilating Latour's approach is that those who do so can have nothing to say to those who continue to be concerned about what they see as 'science-society' relations. The links between the academic science studies community, on the one hand, and scientists and laity, on the other, will be well and truly broken. The radical originality and wit of Latour's approach is hugely attractive. But many scholars will require a better understanding of the foundations of that work and a better sense of where it leads before they decide to pay the price.

Steven Shapin is Reader in the Science Studies Unit, University of Edinburgh, 34 Buccleuch Place, Edinburgh EH8 9JT, UK.

\section{Yummy, yummy?}

\section{John Yudkin}

The Paleolithic Prescription: A Program of Diet \& Exercise and a Design for Living. By S. Boyd Eaton, Marjorie Shostak and Melvin Konner. Harper \& Row: 1988. Pp.306. \$17.95*

MucH has been written about the possible causes of the rise in prevalence of coronary heart disease, diabetes and some sorts of cancer, mostly in the wealthier countries but now also being seen in parts of the Third World. One source of clues for the change in disease pattern lies in the comparison of the life-styles of the populations of places where the incidence of these diseases is very different (such as North America and Western Europe, against the non-industrialized nations of areas of Africa, South America and Asia).

Such comparisons have been the main reason for the widespread belief that at least some of the diseases of affluence are caused by diets low in fibre, because the diets of many countries that are largely free from these diseases are fibre-rich. This approach makes the assumption that the ideal life-style of the human race, and one to which we should return, is that of people living in pre-industrialized countries. But it is difficult to sustain such an argument in view of their lower stature,

* To be published in Britain in July 1989 by Angus \& Robertson, under the title The Stone Age Health Programme. Price will be $£ 4.95$, paperback only. style. They derive their evidence both from palaeontology and from the few tribes that still practise a largely hunting and gathering way of life. The authors elaborate their thesis in a splendidly readable, simple and lively style that seems most convincing.

It would be good to be able to add that the result is flawless exposition, but there are indeed flaws. Some of the suggestions are beside the point, such as avoiding oysters because they are rich in cholesterol; not many individuals regularly consume oysters as an important part of their diet. Some of the assertions are unproven and unlikely (that a low intake of fibre or of carotene can cause cancer), while others are quite unwarranted (that most people are short of calcium and that even those individuals that follow the "Paleolithic prescription" might be better off by taking vitamin supplements).

But the main flaw is the authors' failure to discuss those characteristics of human biology without which neither the Neolithic revolution nor the industrial revolution could have taken place. The invention of agriculture, with its revolutionary changes from a nomadic to a sedentary lifestyle, and from a diet rich in meat to one rich in starchy foods, was possible only because the human species is omnivorous, a quality that it shares with only a few other species such as the rat and the pig. The technological changes of the industrial revolution made it possible increasingly to produce new foods by separating the qualities of palatability from the qualities of nutritional value. Up to that time, it was true for all species that the foods they liked were the foods they needed: it is no longer true that, for human beings, palatability is an infallible guide to nutritional value.

It is also wrong to claim that the "Paleolithic prescription" is new, or even, as the publisher says, "groundbreaking". The idea has been around for at least 30 years; for example, it appeared in an article in The Lancet in 1956 and has been refined and elaborated in many later publications. We can now understand why our sugar consumption is so huge; it is not because, as the authors say, "developers of sugar beet and sugar cane plantations, together with industrialists, food technologists and advertisers, have encouraged" us to take more and more sugar-rich foods and drinks, but simply because we like them. Food manufacturers, technologists and others have devoted the same amount of energy and expertise to try and induce people to take food yeast; they have signally failed to do so simply because people don't like the taste of yeast. The omission of such considerations greatly detracts from the value of this book.

John Yudkin, 20 Wellington Court, London NW8 9TA, UK, is Emeritus Professor of Nutrition in the University of London. 